\title{
IN SITU STUDY OF DISLOCATION BEHAVIOR IN COLUMNAR AI THIN FILM ON Si SUBSTRATE DURING THERMAL CYCLING*
}

\author{
Charles W. Allen*, Herbert Schroeder**, and Jon M. Hiller*** \\ *Materials Science Division \\ Argonne National Laboratory \\ 9700 S. Cass Ave. \\ Argonne, IL 60439 \\ **Institute für Festkörperforschung, \\ Forschungszentrum Jülich $\mathrm{GmbH}, 52425$ \\ Jülich, Germany \\ ***Madison Area Technical College \\ Madison, WI 53704

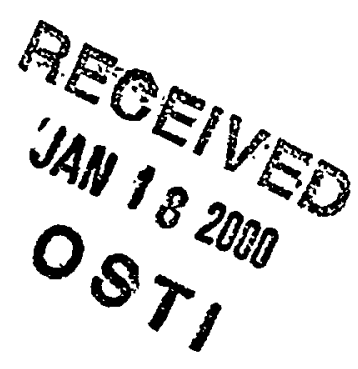

November 1999

The submitted manuscript has
been created by the University of
Chicago as Operator of Argonne
National Laboratory ("Argonne")
under Contract No. W-31-109-
ENG-38 with the U.S. Department
of Energy. The U.S. Government
relains for itself, and others
acting on its behalf, a paid-up,
non exclusive, irrevocable
worldwide license in said article
to reproduce, prepare derivative
works, distribute copies to the
public, and perform publicly and
display publicly, by or on behalf
of the Government.

Paper to be presented at the Fall MRS Meeting, Boston, MA, November 29 - December 3, 1999.

*Work supported by the U. S. Department of Energy, Office of Basic Energy Sciences, under Contract W-31-109-Eng-38. 


\section{DISCLAIMER}

This report was prepared as an account of work sponsored by an agency of the United States Government. Neither the United States Government nor any agency thereof, nor any of their employees, make any warranty, express or implied, or assumes any legal liability or responsibility for the accuracy, completeness, or usefulness of any information, apparatus, product, or process disclosed, or represents that its use would not infringe privately owned rights. Reference herein to any specific commercial product, process, or service by trade name, trademark, manufacturer, or otherwise does not necessarily constitute or imply its endorsement, recommendation, or favoring by the United States Government or any agency thereof. The views and opinions of authors expressed herein do not necessarily state or reflect those of the United States Government or any agency thereof. 


\section{DISCLAIMER}

\section{Portions of this document may be illegible in electronic image products. Images are produced from the best available original document.}




\section{IN SITU STUDY OF DISLOCATION BEHAVIOR IN COLUMNAR AI THIN FILM ON Si SUBSTRATE DURING THERMAL CYCLING}

CHARLES W. ALLEN ${ }^{\star}$, HERBERT SCHROEDER ${ }^{\star \star}$, and JON M. HILLER ${ }^{\star * *}$

* Materials Science Division, Argonne National Laboratory, Argonne, IL 60439 allen@aaem.amc.anl.gov

** Institute für Festkörperforschung, Forschungszentrum Jülich $\mathrm{GmbH}, 52425$ Jülich, Germany

*** Madison Area Technical College, Madison, WI. 53704

\section{ABSTRACT}

In situ transmission electron microscopy ( $150 \mathrm{kV}$ ) has been employed to study the evolution of dislocation microstructures during relatively rapid thermal cycling of a $200 \mathrm{~nm} \mathrm{Al}$ thin film on Si substrate. After a few thermal cycles between 150 and $500^{\circ} \mathrm{C}$, nearly stable Al columnar grain structure is established with average grain less than a $\mu \mathrm{m}$. On rapid cooling $\left(3-30+{ }^{\circ} \mathrm{C} / \mathrm{s}\right)$ from $500^{\circ} \mathrm{C}$, dislocations first appear at a nominal temperature of $360-380^{\circ} \mathrm{C}$, quickly multiplying and forming planar glide plane arrays on further cooling. From a large number of such experiments we have attempted to deduce the dislocation evolution during thermal cycling in these polycrystalline Al films and to account qualitatively for the results on a simple dislocation model.

\section{INTRODUCTION}

A wide variety of phenomena may contribute to the kinetics of failure of systems of electrical interconnects, such as electromigration or stress-induced voiding. A large number of studies have been reported both for line and pad geometries, many of which, of course, appear in the proceedings of MRS Symposia in this and related series. In a thin metallization on a rigid substrate individual grains of the metallization are highly constrained mechanically. Al is very ductile and elastically compliant than Si which are relatively brittle but strong, especially in compression, and more rigid elastically (Young's moduli: $\mathrm{Al}$ is $72 \mathrm{GPa}$; $\mathrm{Si}$ is $130 \mathrm{GPa}$ ). In parallel with these differences, Al also has the much larger thermal expansion coefficient (Al: $25 \times 10^{-6}$; Si: $\left.3.5 \times 10^{-6}\right)$. The study which we describe attempts to isolate a single phenomenon, namely the compensation of differential thermal strain by glide for the case of rapid cooling and heating $\left(3-30+{ }^{\circ} \mathrm{C} / \mathrm{s}\right)$ in order to suppress other relaxation and recovery phenomena. Thereby we emphasize the resulting mechanical response of the material system, which we can observe in situ by transmission electron microscopy. In a sense this is at the opposite extreme of the earlier study by Keller et al. [1] for thermal cycling of thin Cu films on $\mathrm{Si}$, which employs very slow heating and cooling rates $\left(6^{\circ} \mathrm{K} / \mathrm{min}\right)$. In our case we also restrict ourselves to thin film (pad) geometry.

\section{EXPERIMENT}

\section{TEM Specimen Preparation and Instrumentation}

The TEM specimens employed are very similar in fabrication to those described previously for an electromigration study of Al interconnects by Heinen, Schroeder

* Work supported by the U. S. Department of Energy, BES-Materials Sciences, under Contract W-31-109-Eng-38. 
and Schilling [2], polycrystalline Al films replacing Al lines. Essentially the composite specimen consists of $200 \mathrm{~nm}$ of Al, e-beam deposited at $250^{\circ} \mathrm{C}$ on $120 \mathrm{~nm}$ of noncrystalline silicon nitride on a $300 \mu \mathrm{m}$ thick [100] Si wafer, $3 \mathrm{~mm}$ in diameter. The electron-transparent specimen results from chemically thinning the Si from its patterned backside to the nitride which acts as an etchstop, leaving a square window in the Si approximately $20 \mu \mathrm{m}$ across. A total of 6 specimens were examined in this study, each of which was subjected to as many as 20 thermal cycles. In situ thermal cycling experiments were performed in either an Hitachi H-900ONAR equipped with a Gatan 622 high resolution video camera or a Philips CM-30 equipped with a Gatan 676 CCD camera. The TEMs were operated at $150 \mathrm{kV}$ to avoid electron-induced irradiation damage of the Al. Specimens were installed, Al side down, in Gatan water-cooled, double tilt heating holders. Dark field images during thermal cycling were recorded on videotape in S-VHS without frame averaging.

\section{Experimental Procedures}

Dark field imaging for a variety of diffraction conditions was employed for the thermal cycling experiments. In the usual cooling and heating cycle, the TEM specimen was (1) held at the maximum temperature (usually $500^{\circ} \mathrm{C}$ ) for several minutes to fully anneal any residual defect structure, (2) rapidly cooled to typically $\sim 150^{\circ} \mathrm{C}$ by quickly reducing the heater current to zero and (3) reheated to the maximum temperature. Under these conditions on cooling the indicated cooling rates were approximately 31 ${ }^{\circ} \mathrm{C} / \mathrm{s}$ at $440^{\circ} \mathrm{C} ; 8.4^{\circ} \mathrm{C} / \mathrm{s}$ at $380^{\circ} \mathrm{C} ; 6.5^{\circ} \mathrm{C} / \mathrm{s}$ at $340^{\circ} \mathrm{C} ; 5.0^{\circ} \mathrm{C} / \mathrm{s}$ at $280{ }^{\circ} \mathrm{C} ; 3.9^{\circ} \mathrm{C} / \mathrm{s}$ at $240^{\circ} \mathrm{C} ; 3.1^{\circ} \mathrm{C} / \mathrm{s}$ at $200^{\circ} \mathrm{C}$. A number of attempts were made to obtain stereo images of the metastable lower temperature dislocation configurations. Because the glissile perfect dislocations in fcc are of type $0.5 \mathrm{a}<110>\{111\}$, we tried to achieve good 420 dark field conditions at two specimen tilts (such dislocations on all 12 glide systems are in contrast in 420 reflections). This proved to be very difficult because such higher order reflections are very sensitive to even small local variations in grain orientation. To alleviate some of the difficulties in maintaining adequate image contrast with temperature changes which usually cause the migration of bend contours in a given dark field imaging condition, in several cases three dark field channels were preset for a given Al grain prior to thermal cycling; during heating or cooling, the recorded image was then cycled through the three dark field conditions at about three channels per second to extend the amount of information from the changing dislocation microstructure over the entire Al grain.

Image quality

The quality of the dark field images is degraded somewhat by the large specimen thickness $\left(200 \mathrm{~nm}\right.$ of $\mathrm{Al}$ on $120 \mathrm{~nm}$ of $\mathrm{SiN}_{\mathrm{x}}$ ) relative to the electron energy (150 keV). Image focus does not change perceptively during thermal cycling, indicating that there is little bending associated with the thermal stresses. Slight bending is very sensitively detected, however, by changes in dark field imaging conditions on heating or cooling. For example, in an Al film thickness of thickness $t$, a range in grain orientation over which a given dark field image can be formed $\Delta \sigma \approx 2 /\left|g_{n u}\right| t$, where $g_{n u}$ is the reciprocal lattice vector for the imaging reflection, amounts only to about 0.1 deg for the 200 reflection of Al. A number of attempts were made to do stereo imaging of dislocation structures after cooling but unfortunately the quality was not satisfactory for conclusive deduction of the 3D aspects of the dislocation microstructures. 


\section{RESULTS AND DISCUSSION}

\section{Dislocation sources}

While the results of stereo imaging attempts ranged from nil to suggestive, the dislocations in every case which we examined appear to emanate at or near the juncture of Al film grain boundaries and the non-crystalline nitride layer where material compatibility probably is severely tested due to thermal stresses. In several instances it was possible to image adjacent grains simultaneously to determine whether the boundary between them acts systematically in supplying dislocations to both grains. In all cases, there appeared to be no clear relationship. However, because of the difference in grain orientations with respect to the system of thermal stresses, in general similar dislocation activity did not occur in neighboring grains at a given temperature when neighboring grains were imaged simultaneously. Of course, the relief of thermal stress by dislocation production in one grain must influence this process in neighboring grains to some extent as well.

\section{Reversibility of dislocation glide on cooling and reheating}

The first column of Fig. 1 is a sequence of dark field TEM images recorded during rapid cooling from 500 to $135{ }^{\circ} \mathrm{C}$, showing the development of dislocation structures within a near [110] oriented Al grain in the thin film. The second column of Fig. 1 is the sequence for the same Al grain during rapid reheating to $500^{\circ} \mathrm{C}$. The temperatures are those indicated for the heated specimen cup, which lead the actual temperature of the imaged area by some amount which depends on the cup cooling rate. On cooling the dislocation arrays form abruptly from grain boundaries, gliding and increasing in dislocation number in a series of abrupt jumps. On immediate reheating from $135^{\circ} \mathrm{C}$, as indicated in the second column, the dislocations retreat in the same abrupt manner to the boundaries from which they came. After a $5 \mathrm{~min}$ anneal at $500^{\circ} \mathrm{C}$, the cycle was repeated, as shown in the third column of Fig. 1. The resulting dislocation arrangements during cycling are remarkably reproducible and, in fact, remain almost reproducible over as many as 10 thermal cycles of this sort. If, however, the specimen is allowed soak at $\sim 180^{\circ} \mathrm{C}$ for 10 minutes, sufficient recovery occurs to alter subsequent behavior. The equivalent strain in the Al which is accommodated by plastic deformation over the $365^{\circ} \mathrm{C}$ temperature interval of Fig. 1 is roughly half the thermal strain (the thermal strain is approximately $\Delta \alpha_{1} \Delta T=$ $0.78 \times 10^{-2}$ for the average thermal expansion coefficients of Si and Al of 3.5 and 25 $\times 10^{-6}$, respectively) because a yield stress of about $450 \mathrm{MPa}$ was extrapolated from data in ref. 4 which corresponds to a strain of $0.4 \times 10^{-2}$. Evidently for the dislocation density required to accommodate this strain, the leading dislocations do not have to break the native oxide barrier, the dislocations which we see terminate on Al grain boundaries. In addition, the dislocations do not appear to be pinned by the Al/SiN interface as suggested by Fig. 14 in ref. [3]. A theoretical treatment of the stresses as a function of temperature in an $\mathrm{Al}$ alloy film on $\mathrm{Si} / \mathrm{SiO}_{2}$ in the temperature interval $20-450^{\circ} \mathrm{C}$ has been given in the thesis by Burges [6]. Some of the data and the resulting fit equation are published in ref. [4].

\section{Spacing of dislocations in glide bands}

The spacing of leading dislocations in a glide band is generally slightly greater than the spacing of those nearer the source, yielding what appears as a gentle reverse pileup. Stress is relieved (plastic strain results) as dislocations move as far as possible. To 
COOLING
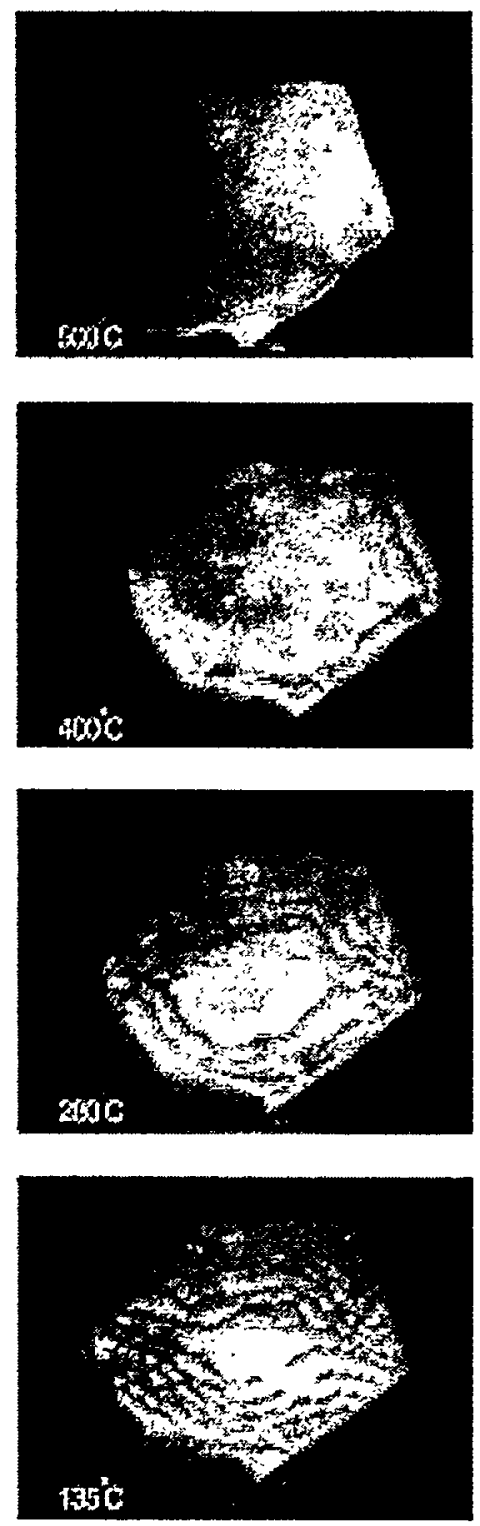

HEATING
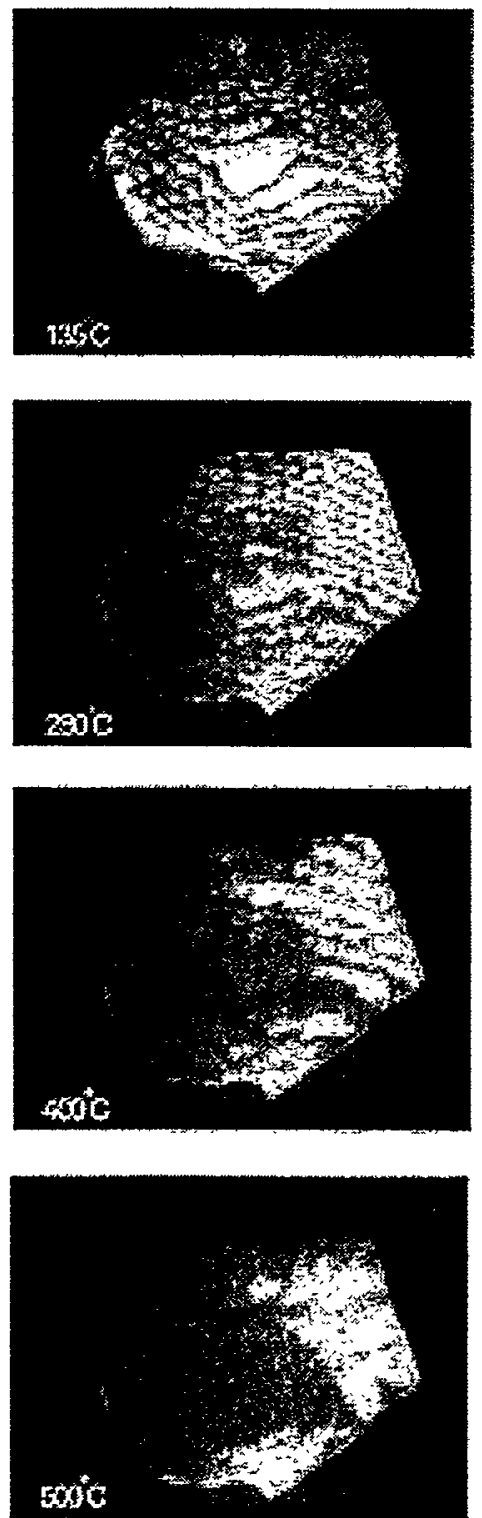

COOLING
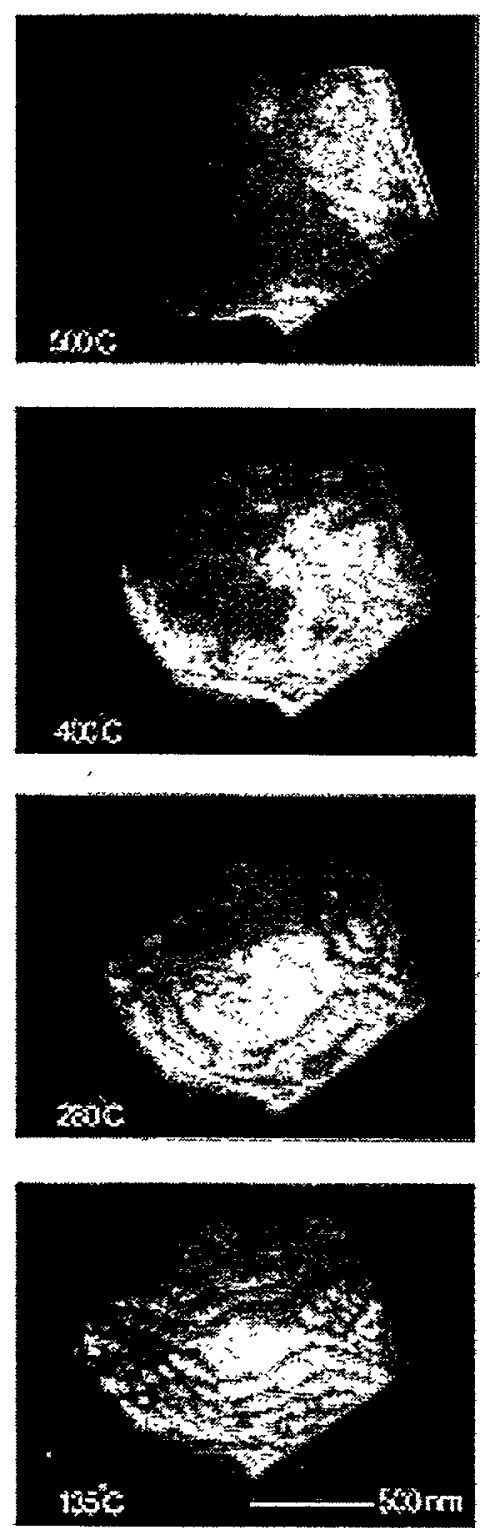

FIG. 1. Sequence showing dislocation formation and disappearance on cooling (column 1), heating (column 2) and cooling again (column 3) between 500 and $135^{\circ} \mathrm{C}$ in a near [110] Al grain.

a good approximation one expects the $200 \mathrm{~nm} \mathrm{Al} \mathrm{film} \mathrm{during} \mathrm{cooling} \mathrm{to} \mathrm{experience} \mathrm{an}$ essentially uniform biaxial system of stress. However, there may be small deviations from this homogeneous condition near the $120 \mathrm{~nm}$ nitride layer which may be responsible for the several rather subtle effects. These effects include the anamolous reverse pileup effect mentioned above and the relaxation of lead dislocations away from their original source during reheating even after a number of dislocations have collapsed back into their source (in column 2 of Fig. 1, compare the images for 135 and $280^{\circ} \mathrm{C}$ ). An arguable interpretation of this is that the small residual stress at the $\mathrm{Al} / \mathrm{SiN}_{\mathrm{x}}$ interface due to differential thermal expansion there is decreasing, allowing the lead dislocations to relax slightly toward the surface. At the same time the decreasing dominant uniform thermal stress in the Al causes dislocations nearest the 
source to retreat and disappear, as in the Bauschinger effect. The dislocations always appear to be very waving in shape.

\section{A simple dislocation model}

Dislocations in crystals may move, relieving stresses (and hence lattice distortions) of whatever origin, by glide (slip) or by climb (which requires diffusion). Frost [3] has presented a helpful general review of deformation mechanisms in thin films, including the above. The glide and/or climb forces acting on a given dislocation are governed by the Peach-Koehler relation [4] which represents the interaction of the stress field of a dislocation with any other stress field; if glide or climb results, the direction is such as to attempt to reduce the overall strain energy. Fig. 2 illustrates qualitatively the glide $(G)$ and climb (C) forces on four pure edge dislocations (I -IV), oriented differently with respect to a simple tensile stress field in a hypothetical single crystal, involving three slip systems. Dislocations I and IV experience both glide and climb force components, II experiences no force (neither glide nor climb would contribute to the longitudinal strain) and III experiences only a climb force (adding atoms below it makes the crystal longer, thereby contributing to the longitudinal strain). The thin Al film on the massive Si substrate and over the small window of the TEM specimen experience biaxial tension on cooling. Of the 12 dislocation glide systems available in Al, those which experience the largest resolved shear stress (largest glide force) will be activated. As few as two such systems with orthogonal Burgers vectors are sufficient to accommodate the increasing stresses on cooling by dislocation formation and glide.

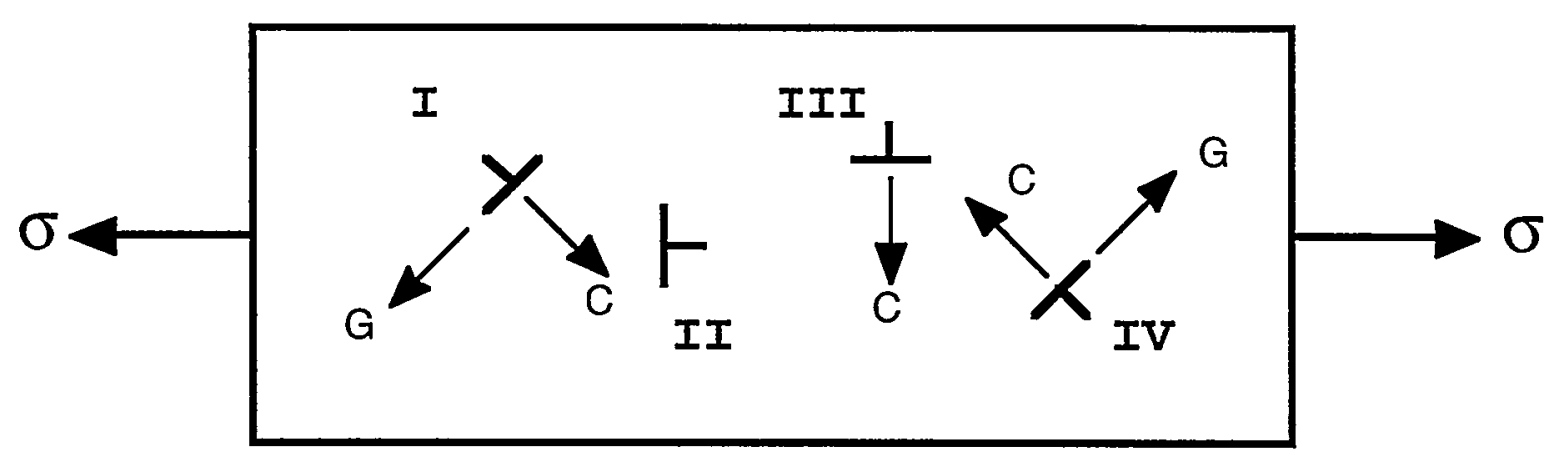

FIG. 2. Glide (G) and climb (C) forces on variously oriented edge dislocations in a tensile stress field.

For a simple example, consider Fig. 3. The contribution to stress relaxation due to dislocation glide is quite simple to estimate. To illustrate the role of plastic deformation of the Al in the process of thermal stress relaxation, Fig. 3 shows a set of identical edge dislocations in a thin film, which have emanated from the grain boundary/substrate intersection at the lower left $(O)$ and moved by glide toward the surface S. Dislocation 6 has moved a fraction $\left(t / t_{0}\right)$ of the distance OS. If such a dislocation were to sweep over its entire glide plane, an increment of plastic strain in the direction of the grain dimension $D$ results, the magnitude of which is just the component of the Burgers vector $b$ along the direction of $D$, divided by $D$. For dislocation 6 which has swept out only a portion of its possible glide surface, its contribution to the plastic strain would be $\Delta \varepsilon=\left(t / t_{0}\right)(1 / D)|b| \cos \Theta$ where $\Theta$ is the angle between $b$ and $D$. The total effective strain due to glide of $N$ identical dislocations is $\varepsilon_{N}=N\left(t / t_{0}\right)_{A V}(1 / D)|b| \cos \Theta$ and in our case this manifests itself as a 


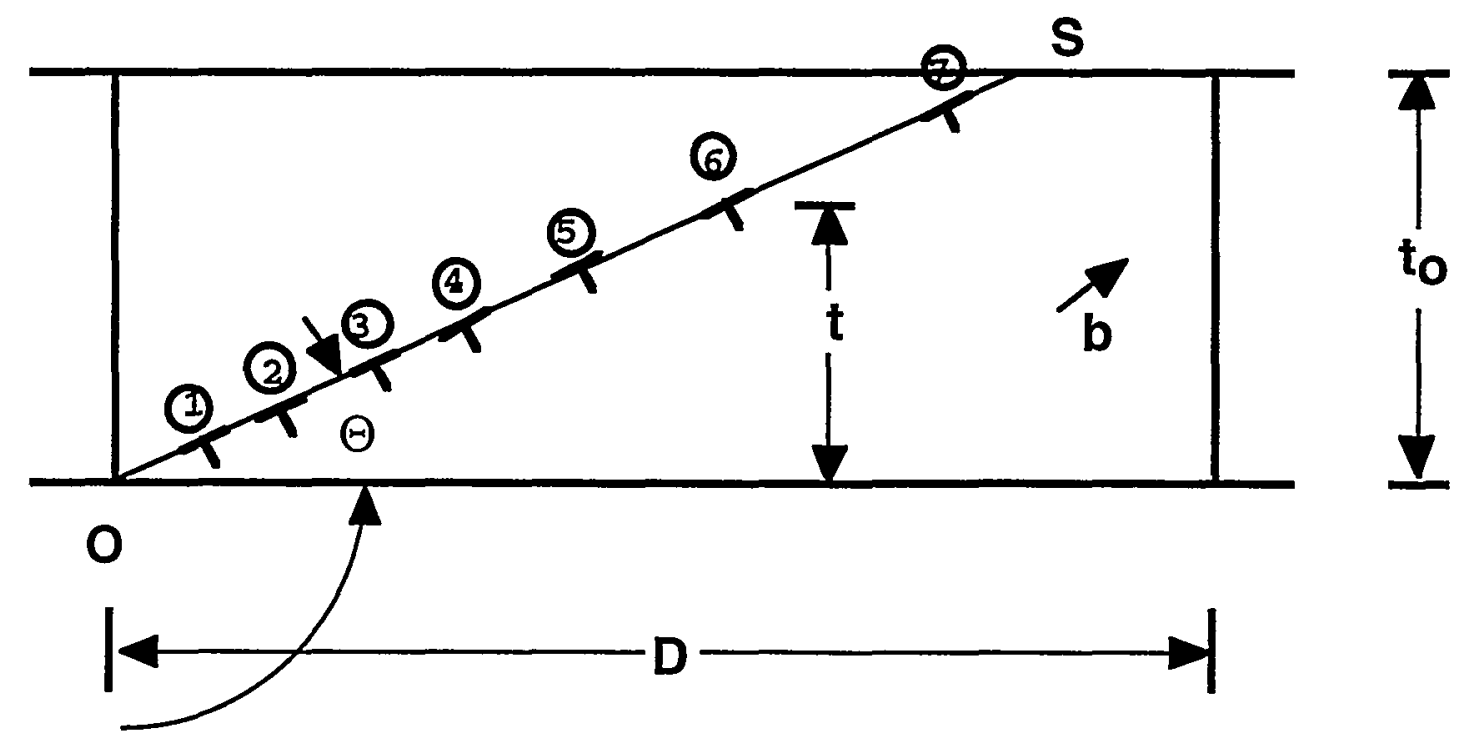

FIG. 3. Band of edge dislocations from origin $\mathrm{O}$ in Al, which relieve stress due to differential thermal contraction (expansion), as they glide toward surface $S$.

reduction in thermal stress; that is, the mechanical constraint imposed by the neighboring grains does not allow a physical change in shape of the grain to be realized (unless the change in stress can cause grain boundary migration by glide). Taking $\Theta=35^{\circ}$ as in a [110] grain, $D=500 \mathrm{~nm}, b=0.28 \mathrm{~nm}$, half the total effective thermal strain to be $0.39 \times 10^{-2}$ as estimated above and the average area fraction of glide plane swept by the dislocation band to be 0.5 , the number of dislocations $\mathrm{N}=$ 14. The number of dislocations in one of the two bands in Fig. 1 at $135^{\circ} \mathrm{C}$ appears to be 16 , in good agreement with this estimate.

\section{REFERENCES}

[1] R. -M. Keller, W. Sigle, S. P. Baker, O. Kraft, and E. Arzt, Mat. Res. Soc. Symp. Proc. 436 (1997) 221-226.

[2] D. Heinen, H. Schroeder, and W. Schilling, Mat. Res. Soc. Symp. Proc. 473 (1997) 375-380.

[3] H. J. Frost, Mat. Res. Soc. Symp. Proc. 265 (1992) 3-14.

[4] U. Burges, H. Helneder, H. Körner, H. Schroeder, and W. Schilling, Mat. Res. Soc. Symp. Proc. 338 (1994) 247-252.

[5] J. P. Hirth and J. Lothe, Theory of Dislocations (McGraw-Hill, New York, 1968) p. 99.

[6] U. Burges, Thesis, RWTH Aachen, Germany, 1995; published as: Report of the Forschungszentrum Jülich $\mathrm{GmbH}$, Jülich, Germany (Report Jül-3112, Sept. 1995). 